\title{
Chemical bonding and charge density distribution analysis of undoped and lanthanum doped barium titanate ceramics
}

\author{
J MANGAIYARKKARASI $^{\mathrm{a}, *}, \mathrm{R}$ SARAVANAN ${ }^{\mathrm{b}}$ and MUKHLIS M ISMAIL ${ }^{\mathrm{c}}$ \\ ${ }^{a}$ PG and Research Department of Physics, NMSSVN College, Nagamalai, Madurai, Tamil Nadu, 625019 India \\ ${ }^{b}$ Research Centre and PG Department of Physics, The Madura College, Madurai, Tamil Nadu, 625011 India \\ ${ }^{\mathrm{c}}$ School of Applied Science, University of Technology, Baghdad, Iraq \\ e-mail: mangai.jp@gmail.com; saragow@gmail.com; mmismail009@gmail.com
}

MS received 13 May 2016; revised 5 October 2016; accepted 5 October 2016

\begin{abstract}
A-site deficient, Lanthanum substituted $\mathrm{Ba}_{1-\mathrm{x}} \mathrm{La}_{2 \mathrm{x} / 3} \mathrm{TiO}_{3} \quad(\mathrm{x}=0.000,0.005,0.015,0.020$ and 0.025 ) ceramics have been synthesized by chemical route. The effects of lanthanum dopant on the $\mathrm{BaTiO}_{3}$ lattice and the electron density distributions in the unit cell of the samples were investigated. Structural studies suggested the reduction in cell parameters and shrinkage in cell volume with the increase in lanthanum content. Chemical bonding and electron density distributions were examined through high resolution maximum entropy method (MEM). The mid bond electron density values revealed the enhancement of covalent nature between titanium and oxygen ions and predominant ionic nature between barium and oxygen ions. Average grain sizes were estimated for the undoped and doped samples. SEM investigations showed the existence of smaller grains with large voids in between them.
\end{abstract}

Keywords. Ceramics; charge density; X-ray diffraction; bonding; microstructure

\section{Introduction}

Ferroelectric perovskite materials are an extremely important class of ceramics. Among several candidate materials, the most extensively studied, environmentfriendly ferroelectric oxide is barium titanate $\left(\mathrm{BaTiO}_{3}\right){ }^{1}$ Due to its promising structural, electrical properties and chemical stability the titanate related compounds promote new scientific innovations in recent years. ${ }^{2,3}$ In commercial wireless communication systems, technological advancements have been made recently with the usage of barium titanate ceramic materials due to their low dissipation factor, low loss and high dielectric constant. ${ }^{4,5}$ Materials derived from $\mathrm{BaTiO}_{3}$ based compositions have attracted a good deal of attention because of their electro-optic and piezoelectric properties. $^{6,7}$ With the partial substitution of $\mathrm{Ba}$ or $\mathrm{Ti}$ ions in $\mathrm{BaTiO}_{3}$, the performances can be further manipulated and improved. ${ }^{8}$ In $\mathrm{BaTiO}_{3}$ doped with rare earth cations such as $\mathrm{La}^{3+}, \mathrm{Dy}^{3+}, \mathrm{Sm}^{3+}, \mathrm{Y}^{3+}$ and $\mathrm{Lu}^{3+}$, the micro structural and electrical properties are modified dramatically. Among them, La is a perfect doping material of great importance. ${ }^{9}$ However, the role of the specific dopant on the electrical property depends on the

*For correspondence substitution site. A trivalent ion acts as a donor, when the substitution occurs at $\mathrm{Ba}$ site, whereas it behaves as an acceptor when the substitution occurs at Ti site. ${ }^{10}$ Doping mechanisms of $\mathrm{La}^{3+}$ on $\mathrm{BaTiO}_{3}$ have been extensively studied over the past several decades. Substitution of $\mathrm{La}^{3+}$ ions at the Ba site brings more electrons into the system and the material changes from insulator to n-type semiconductor. ${ }^{11}$ Incorporation of $\mathrm{La}^{3+}$ as a donor dopant at relatively lower concentrations $($ at $<1 \%)$ is responsible for the formation of n-type semiconductor, but higher concentrations suppress the grain growth and the semiconductor converts into insulator again. ${ }^{12,13}$ Donor doped $\mathrm{BaTiO}_{3}$ materials exhibit positive temperature coefficient (PTCR) behavior. As a result of this effect, these materials have been ultimately used as thermistors to limit over current, temperature sensors, time delay circuits, overheat protection devices and current stabilizers. ${ }^{14}$

As far as the La doped barium titanate is concerned, surface level and dielectric characterizations have been largely analyzed by various researchers. ${ }^{15,16}$ However, beyond the structural level characterizations, the precise determination of internal electronic level features of a crystalline system is most essential for the present day technological innovations. Thus, the analysis in the lines of bonding features like bond length variation, the mid bond density distributions between the 
atoms in different lattice planes and along various crystallographic directions are very much important because it determines the usability of the material for desired applications. ${ }^{17}$ Evarestor et al.,${ }^{18}$ theoretically analyzed the electronic structure and bonding nature of pure perovskites like $\mathrm{BaTiO}_{3}, \mathrm{PbTiO}_{3}$ and $\mathrm{SrTiO}_{3}$ by using Hatree - Fock method and density functional theory. Influence of electronic charge redistribution on the semiconductivity of $\mathrm{BaTiO}_{3}$ and bonding natures of $\mathrm{ABO}_{3}$-type perovskites are also reported. ${ }^{19,20}$ For La doped $\mathrm{BaTiO}_{3}$, experimental charge density studies are hardly available and hence in the present work, the core aim is to analyze the electron density distributions and accurate bond length variations in the $\mathrm{Ba}_{1-\mathrm{x}} \mathrm{La}_{2 \mathrm{x} / 3} \mathrm{TiO}_{3}$ $(\mathrm{x}=0.000,0.005,0.015,0.020$ and 0.025$)$ system. The accurate electronic structure inside the unit cell can be successfully analyzed by constructing charge density from the X-ray structure factors using the best available, less biased mathematical tool, such as maximum entropy method [MEM]. ${ }^{21}$ This method was introduced in X-ray crystallography by Collins. ${ }^{22}$ Electron density distributions through MEM method is reported for undoped $\mathrm{BaTiO}_{3}$ by Rother et al. ${ }^{23}$

In the present work, the surface morphology, structural modifications and electron density distributions between the atoms in the unit cell of the grown samples have been analyzed using scanning electron microscopy (SEM) and powder X-ray diffraction techniques and an effort has been made to correlate the observed properties with electron density analysis. This present report can be considered as the first and precise attempt in clear visualization of bonding nature between atoms in the $\mathrm{Ba}_{1-\mathrm{x}} \mathrm{La}_{2 \mathrm{x} / 3} \mathrm{TiO}_{3}$ system.

\section{Experimental}

$\mathrm{Ba}_{1-x} \mathrm{La}_{2 x / 3} \mathrm{TiO}_{3} \quad(x=0.000,0.005,0.015,0.020$ and $0.025)$ were synthesized by chemical route. $\mathrm{Ba}\left(\mathrm{NO}_{3}\right)_{2}$, $\mathrm{La}\left(\mathrm{NO}_{3}\right)_{3}, \mathrm{TiO}_{2}$ and oxalic acid were used as starting materials. An aqueous solution of barium nitrate and lanthanum nitrate were dissolved in deionized water. Then, appropriate amount of $\mathrm{TiO}_{2}$ was added to oxalic acid solution with continuous stirring to form a suspension. The suspension was treated in ultrasonic bath for 5 min to break the $\mathrm{TiO}_{2}$ agglomerates. The barium nitrate and lanthanum nitrate mixed solution was added dropwise into the suspension of $\mathrm{TiO}_{2}$ in oxalic acid under vigorous stirring. The $\mathrm{pH}$ of the resultant mixture was adjusted to 5 using ammonia solution. The resulting precipitate was filtered out and then washed repeatedly using deionized water, followed by drying at $70^{\circ} \mathrm{C}$ for $8 \mathrm{~h}$. Finally, the dry powder was annealed at $900^{\circ} \mathrm{C}$ for $1 \mathrm{~h}$.
Structural characterization was done using the powder X-ray diffraction intensity data sets collected at Sophisticated Analytical Instrument Facility (SAIF), Cochin University, Cochin, using an X-ray diffractometer (Bruker AXS D8 Advance) with $\mathrm{CuK} \alpha$, monochromatic incident beam $(\lambda=1.54056 \AA)$. The XRD patterns were obtained in the $2 \theta$ range of $10^{\circ}-120^{\circ}$ with the step size of $0.02^{\circ}$. SEM images were recorded using JEOL model JSM-6290LV corresponding to various magnifications $(\times 1500, \times 5000, \times 10000)$ to investigate the surface morphology.

\section{Results and Discussion}

\subsection{Structural analysis using the Rietveld technique}

The prepared powder samples $\mathrm{Ba}_{1-\mathrm{x}} \mathrm{La}_{2 \times / 3} \mathrm{TiO}_{3}$ $(\mathrm{x}=0.000,0.005,0.015,0.020$ and 0.025$)$ were subjected to X-ray diffraction for structural analysis. Except the composition $\mathrm{x}=0.000$, all the remaining samples are non-stoichiometric, exhibiting A-site deficient perovskites according to the structural formula $\mathrm{Ba}_{1-\mathrm{x}} \mathrm{La}_{2 \mathrm{x} / 3} \Delta_{\mathrm{x} / 3} \mathrm{TiO}_{3}$, where $\Delta$ denotes A-site vacancy. Figure 1 (a) shows the raw XRD patterns of $\mathrm{Ba}_{1-\mathrm{x}} \mathrm{La}_{2 \mathrm{x} / 3} \mathrm{TiO}_{3} \quad(\mathrm{x}=0.000,0.005,0.015,0.020$ and 0.025). The experimentally observed powder XRD peaks matched well with those of the Joint Committee on Powder Diffraction Standards (JCPDS) database (PDF\# 05-0626). Existence of well-defined and sharp peaks indicates that all the grown samples are highly crystalline in nature. The noticeable increase in X-ray intensities was also observed for the La doped samples in comparison with the undoped one. With the successive increase in La content, the shift of Bragg peaks towards higher $2 \theta$ angles was observed as shown in the Figure 1(b). This particular trend of shifting of peak positions was attributed to the variation in ionic sizes of $\mathrm{Ba}(1.35 \AA)$ and La $(1.03 \AA) .{ }^{24}$ But, the peak corresponding to $\mathrm{x}=0.015$ composition is shifted towards lower $2 \theta$ value. This unexpected behavior may be due to the slight lattice disorder. In all the prepared samples, some extra reflections corresponding to $\mathrm{Ba}_{6} \mathrm{Ti}_{17} \mathrm{O}_{40}$ were also observed. The existence of these additional phases was reported by several authors. ${ }^{25-27}$

Structural refinement was carried out for the $\mathrm{Ba}_{1-\mathrm{x}} \mathrm{La}_{2 \mathrm{x} / 3} \mathrm{TiO}_{3} \quad(\mathrm{x}=0.000,0.005,0.015,0.020$ and 0.025 ) systems using Rietveld refinement ${ }^{28}$ technique with the software package JANA $2006 .{ }^{29}$ The raw XRD profiles were refined by considering the tetragonal symmetry with $P 4 \mathrm{~mm}$ space group and one formula unit per primitive cell. The initial atomic co-ordinates $(\mathrm{x}, \mathrm{y}, \mathrm{z})$ were taken as $(0,0,0)$ for barium/lanthanum, $(0.5,0.5$, $0.512)$ for titanium, $(0.5,0.5,0.023)$ for $\mathrm{O} 1$ and $(0.5,0$, 

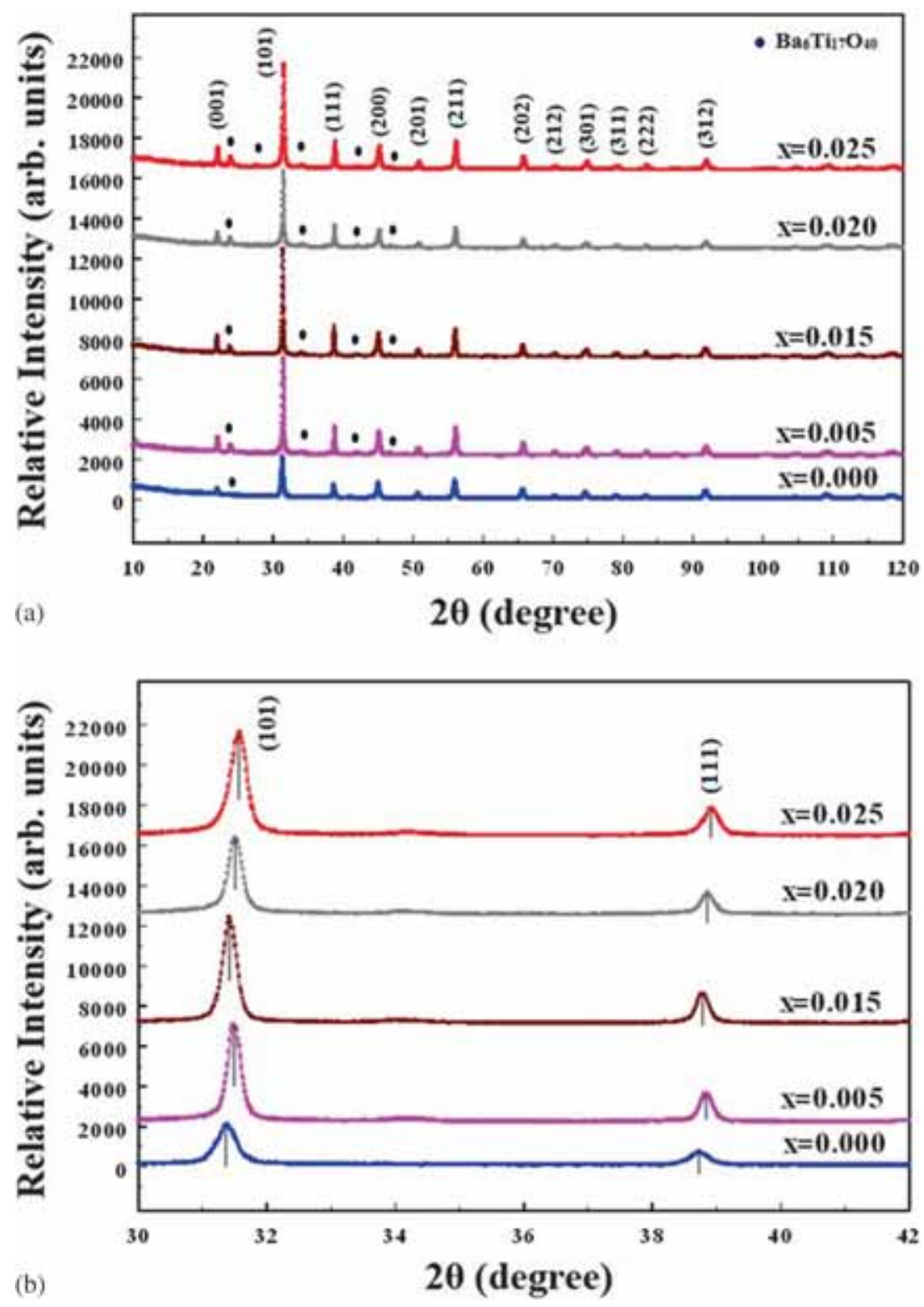

Figure 1. (a) The observed $\mathrm{X}$-ray diffraction patterns of $\mathrm{Ba}_{1-\mathrm{x}} \mathrm{La}_{2 \mathrm{x} / 3} \mathrm{TiO}_{3}$ ( $x=0.000,0.005,0.015,0.020,0.025)$ La doped samples. (b) Shift of Bragg peaks towards higher $2 \theta$ values.

0.486) for $\mathrm{O} 2$ from standard Wyckoff position tables. ${ }^{30}$ Structural parameters such as lattice parameters, atomic coordinates, composition of atoms, shift, scale factors and some other parameters were also refined from the experimentally observed XRD profiles by comparing them with the theoretically constructed profiles. The refined profiles of $\mathrm{Ba}_{1-x} \mathrm{La}_{2 \times / 3} \mathrm{TiO}_{3}(\mathrm{x}=0.000,0.005$, $0.015,0.020$ and 0.025$)$ are given in Figures 2(a-e) respectively.

In these figures, the observed powder patterns are indicated by dots and calculated powder patterns are represented by continuous lines. At the bottom of each figure, the difference between the observed and calculated profiles is shown. The small vertical lines indicate the positions of the Bragg peaks. Refined profile fittings revealed the good matching between the observed and calculated profiles for all five samples. The refinement yielded the satisfactory lattice parameters, cell volumes and reliability indices which are listed in Table 1. The amount of impurity phase $\mathrm{Ba}_{6} \mathrm{Ti}_{17} \mathrm{O}_{40}$ has been estimated and identified in the range of $0.7 \%$ to $12.5 \%$.

Substitution of $\mathrm{La}$ at the $\mathrm{Ba}$ site results in the reduction of lattice parameters and shrinkage in cell volume 

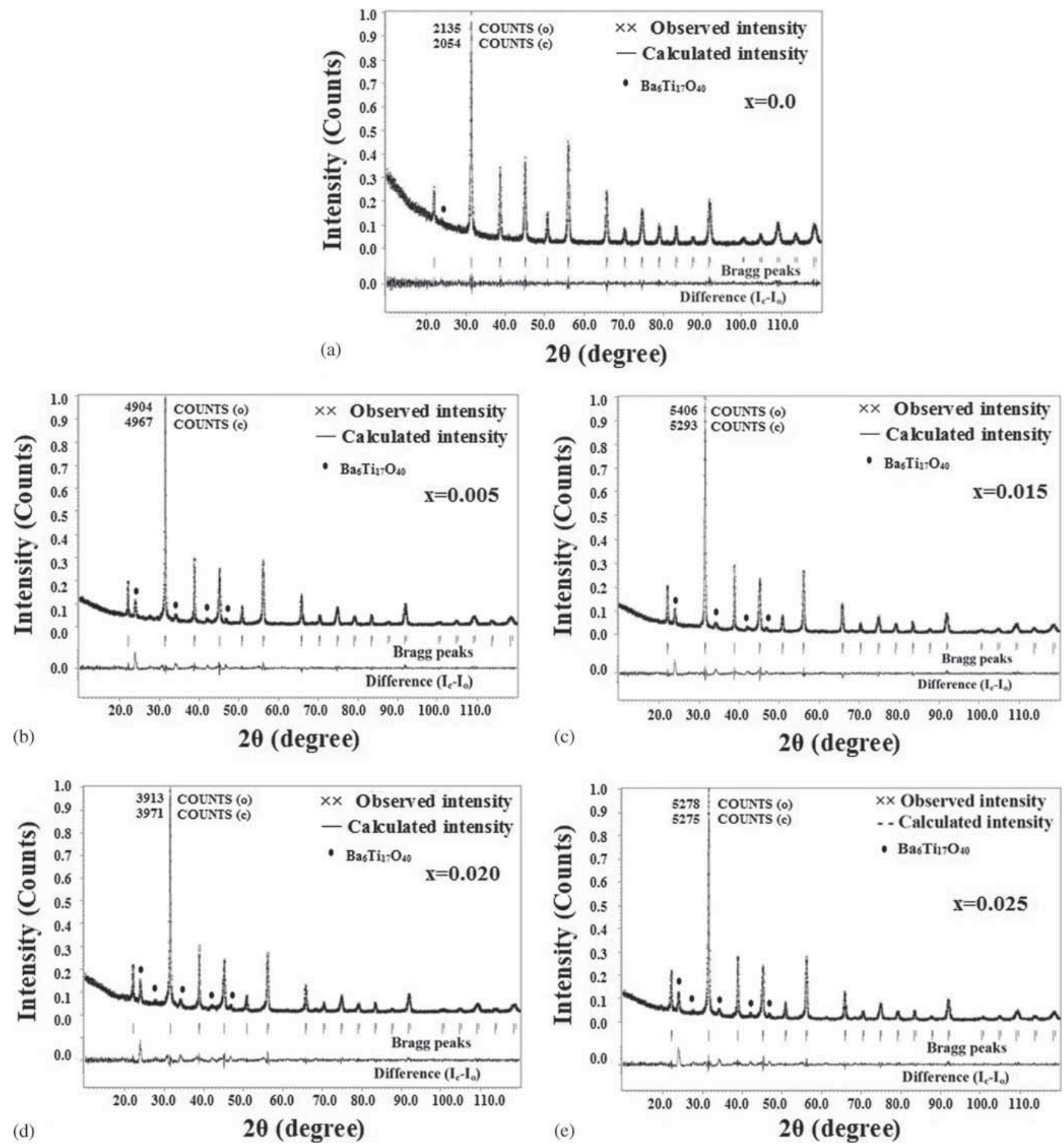

Figure 2. Rietveld refined profiles of $\mathrm{Ba}_{1-\mathrm{x}} \mathrm{La}_{2 \mathrm{x} / 3} \mathrm{TiO}_{3}$ for (a) $\mathrm{x}=0.000$, (b) $\mathrm{x}=0.005$, (c) $\mathrm{x}=0.015$, (d) $\mathrm{x}=0.020$ and (e) $\mathrm{x}=0.025$.

in agreement with the earlier reports. ${ }^{31}$ The average grain sizes of the samples were calculated using Scherrer formula $(\mathrm{t}=0.9 \lambda / \beta \cos \theta)$, where $\mathrm{t}$ is the grain size, $\lambda$ is wavelength of $\mathrm{X}$-ray, $\beta$ is the full width at half maximum and $\theta$ is the Bragg angle. ${ }^{32}$ Average grain sizes were found to be in the range of
$21-36 \mathrm{~nm}$, which is highly comparable with those already reported. ${ }^{33}$ Structure factors which are evolved from the refinement also matched well with the experimentally observed structure factors with low standard errors. These structure factors were used for the charge density analysis. 
Table 1. Structural parameters of $\mathrm{Ba}_{1-x} \mathrm{La}_{2 \times / 3} \mathrm{TiO}_{3}$ obtained from Rietveld refinement.

\begin{tabular}{lllccc}
\hline Parameters & $\mathrm{x}=0.000$ & $\mathrm{x}=0.005$ & $\mathrm{x}=0.015$ & $\mathrm{x}=0.020$ & $\mathrm{x}=0.025$ \\
\hline $\mathrm{a}(\AA)$ & $4.0020(11)$ & $4.0009(6)$ & $3.9996(3)$ & $3.9951(9)$ & $3.9943(10)$ \\
$\mathrm{c}(\AA)$ & $4.0178(14)$ & $4.0217(8)$ & $4.0211(2)$ & $4.0175(11)$ & $4.0166(2)$ \\
$\alpha=\beta=\gamma($ degree $)$ & 90 & 90 & 90 & 90 & 90 \\
Cell Volume $\left(\AA^{3}\right)$ & $64.35(32)$ & $64.37(24)$ & $64.32(12)$ & $63.12(9)$ & $63.08(17)$ \\
Density $(\mathrm{gm} / \mathrm{cc})$ & 6.0161 & 6.0006 & 6.0012 & 6.0131 & 6.0098 \\
$\mathrm{R}_{\text {obs }}(\%)$ & 1.98 & 2.28 & 2.32 & 2.77 & 2.27 \\
$\mathrm{wR}_{\text {obs }}(\%)$ & 2.15 & 2.36 & 2.53 & 2.81 & 2.28 \\
$\mathrm{R}_{\mathrm{p}}(\%)$ & 6.38 & 7.99 & 7.75 & 8.40 & 7.88 \\
$\mathrm{wR}_{\mathrm{p}}(\%)$ & 8.75 & 11.54 & 11.33 & 12 & 11.59 \\
$\mathrm{GOF}$ & 1.06 & 1.50 & 1.49 & 1.53 & 1.58 \\
\hline
\end{tabular}

\subsection{Charge density analysis using MEM technique}

The charge density distributions and the bonding nature between the atoms in any crystalline structure can be accurately achieved using MEM technique. ${ }^{22}$ In this work, MEM computations were carried out by considering $64 \times 64 \times 64$ pixels per unit cell. The software package PRIMA ${ }^{34}$ was adopted for the numerical MEM computations, and the resultant three dimensional and two dimensional electron density maps are plotted using the visualization software VESTA. ${ }^{35}$

The three dimensional charge density distributions of $\mathrm{Ba}_{1-\mathrm{x}} \mathrm{La}_{2 \mathrm{x} / 3} \mathrm{TiO}_{3}$ ( $\mathrm{x}=0.000,0.005,0.015,0.020$ and $0.025)$ are constructed by considering the iso-surface level of $1 \mathrm{e} / \AA^{3}$. Figure 3(a) represents the 3-D view of the unit cell for the undoped sample with (002) plane shaded. Figure 3(b) represents the 3-D view of the unit cell for the undoped sample with (001) plane shaded.

From these pictures, the positions of $\mathrm{Ba}, \mathrm{Ti}, \mathrm{O} 1$ and $\mathrm{O} 2$ atoms and electron density clouds around them are clearly visualized. Barium atoms are situated at the corners, oxygen atoms are at the face centers and titanium atom is at the body centered position of the $\mathrm{BaTiO}_{3}$ unit cell.

Accurate electron density distributions for the particular plane of interest can be clearly visualized and analyzed by constructing two dimensional electron density contour maps. Due to the high resolution of these maps, most precise electron density distributions can be visualized inside the system. Two-dimensional contour maps corresponding to (002) plane of the undoped $\mathrm{BaTiO}_{3}(\mathrm{x}=0.000)$ is shown in the Figure 4(a) and the enlarged view of bonding between $\mathrm{Ti}$ and $\mathrm{O} 2$ atoms is depicted in Figure 4(b). Figures 4(c-f) show the enlarged view of bonding between $\mathrm{Ti}$ and $\mathrm{O} 2$ atoms for the La doped samples. High electron density distributions are seen on the (002) plane. The bonding between titanium and oxygen is partially covalent in nature as a result of hybridization between the $\mathrm{O}-2 \mathrm{p}$ and the Ti-3d orbitals and the two-dimensional contour maps visually show charge sharing between the body centered $\mathrm{Ti}$ and face centered $\mathrm{O}$ atoms.
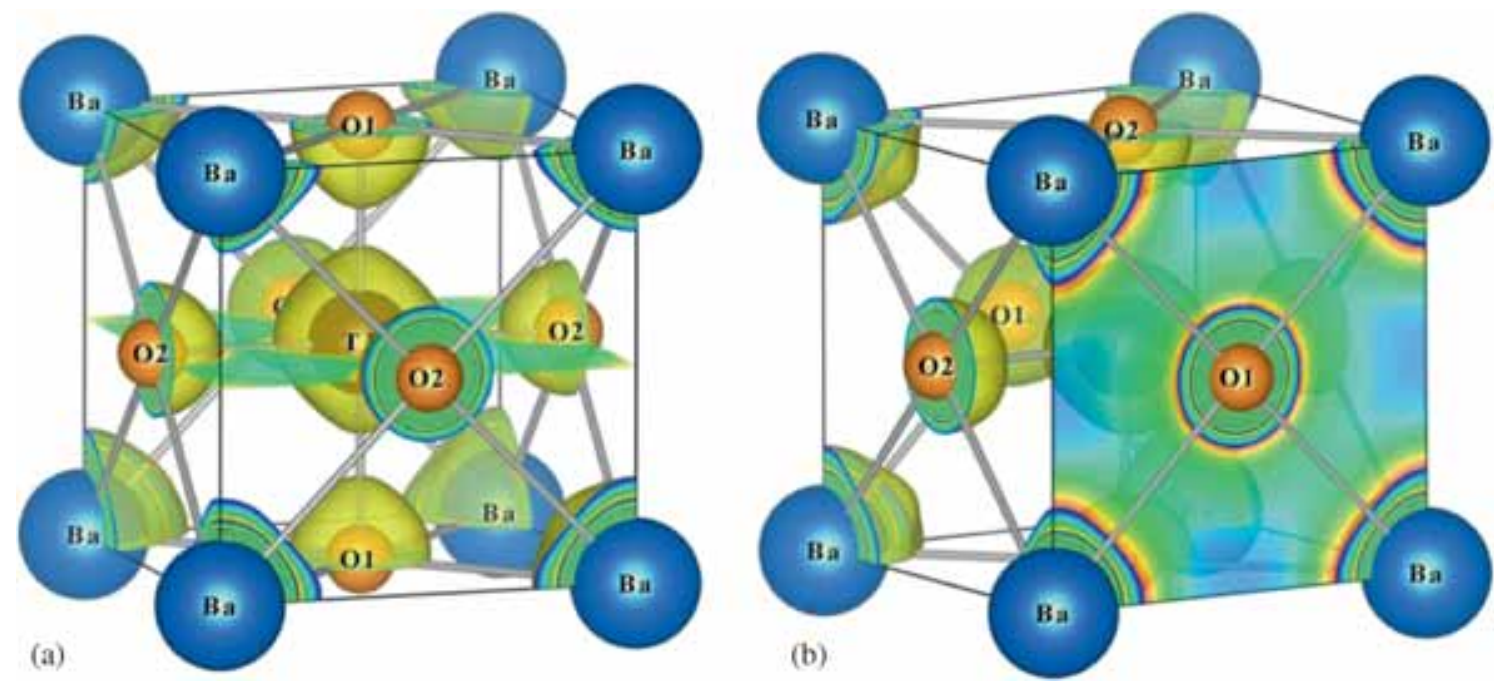

Figure 3. (a) 3D unit cell of BLT with (002) plane shaded (b) 3D unit cell of BLT with (001) plane shaded. 


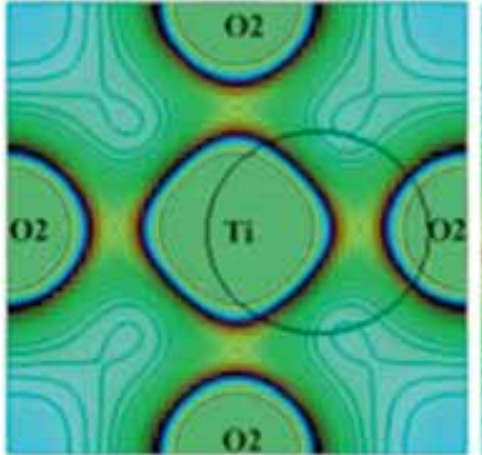

(a)

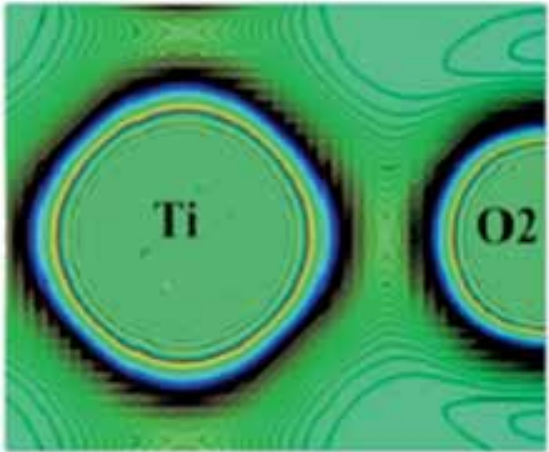

(c)

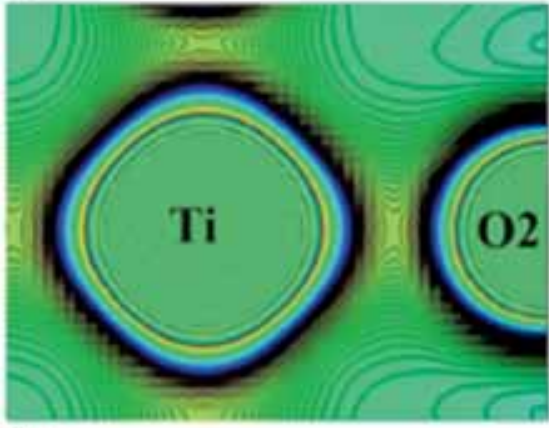

(c)

(b)
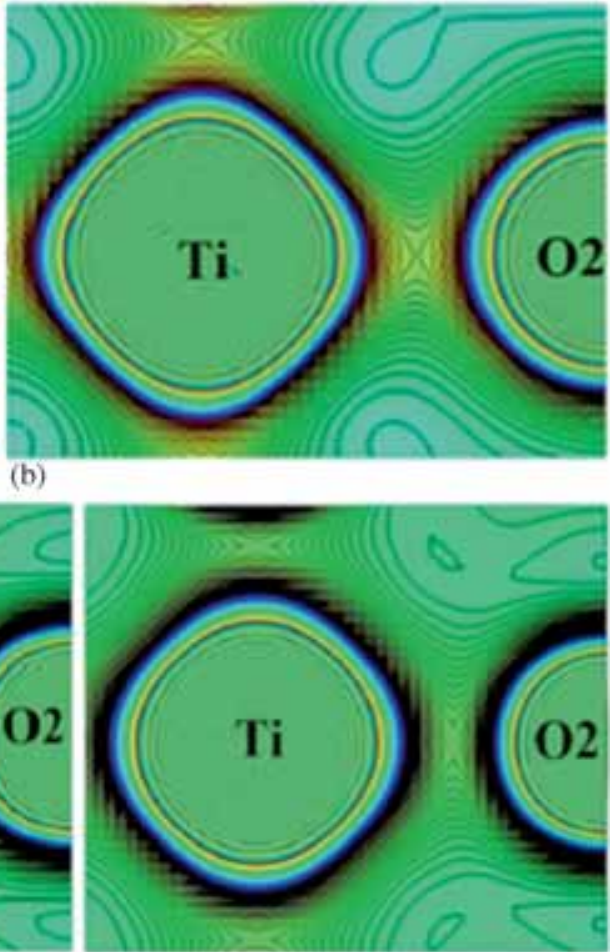

(d)

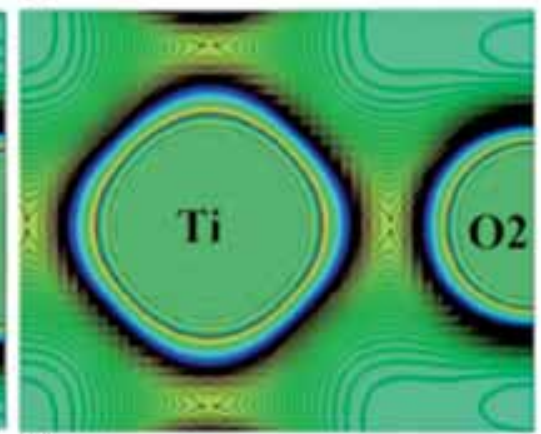

(f)

Figure 4. (a) $2 \mathrm{D}$ electron density distributions on (002) plane for $\mathrm{x}=0.000$. (b), (c), (d), (e) and (f) are enlarged views of bonding between Ti and $\mathrm{O} 2$ atoms for compositions $\mathrm{x}=0.000, \mathrm{x}=0.005, \mathrm{x}=0.015, \mathrm{x}=0.020$ and $\mathrm{x}=0.025$.

Two dimensional contour maps of the undoped $\mathrm{BaTiO}_{3}(\mathrm{x}=0.000)$ for (001) plane is shown in the Figure 5(a) and the enlarged view of bonding between $\mathrm{Ba}$ and $\mathrm{O} 1$ atoms is depicted in Figure 5(b). Figures 5 (c-f) show the enlarged views of bonding between $\mathrm{Ba}$ and $\mathrm{O} 1$ atoms for the La doped samples. Low density charge distributions are visible on the (001) plane around $\mathrm{Ba}$ and $\mathrm{O} 1$ atoms due to the minimum interaction between them. For all compositions, two dimensional MEM maps clearly indicate the predominant ionic nature between barium and oxygen with minute differences due to the small compositional variations.

In order to analyze the electron density distributions and bond length variations in detail, the one dimensional electron density line profiles along $\mathrm{Ba}-\mathrm{O} 1$ and Ti-O2 bonds are drawn. Figures 6 and 7 show the one dimensional line profiles for $\mathrm{Ba}-\mathrm{O} 1$ and $\mathrm{Ti}-\mathrm{O} 2$, respectively. One dimensional electron density profiles depict the uniform distribution of charges between the atoms on both (001) and (002) planes.

The bond lengths and the mid bond density values corresponding to $\mathrm{Ba}-\mathrm{O} 1$ and $\mathrm{Ti}-\mathrm{O} 2$ are given in Table 2 . The bond lengths are found to be decreasing with the successive addition of La, thereby enhancing the bond strength. The small reduction in bond lengths is due to the variations in ionic sizes of $\mathrm{Ba}(1.35 \AA)$ and $\mathrm{La}$

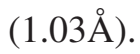

The mid bond density value between $\mathrm{Ba}$ and $\mathrm{O} 1$ for undoped sample is $0.309 \mathrm{e} / \AA^{3}$. For La doped samples the mid bond density values are found to be $0.278 \mathrm{e} / \AA^{3}$, $0.283 \mathrm{e} / \AA^{3}, 0.293 \mathrm{e} / \AA^{3}$ and $0.288 \mathrm{e} / \AA^{3}$. These mid bond density values authenticate the predominant ionic 


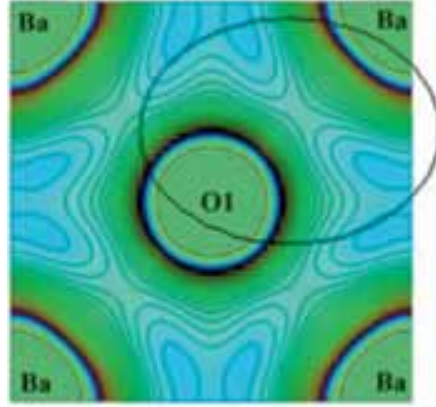

(a)

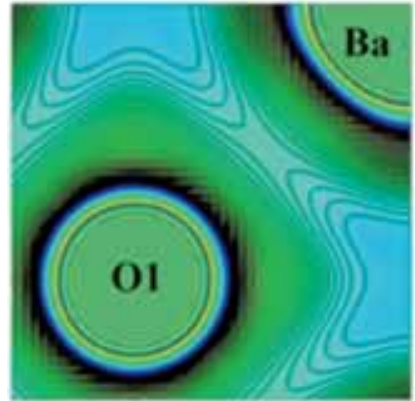

(c)

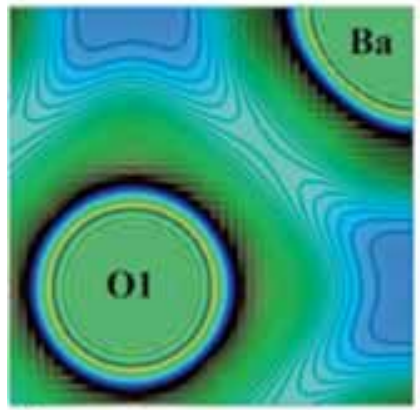

(e)

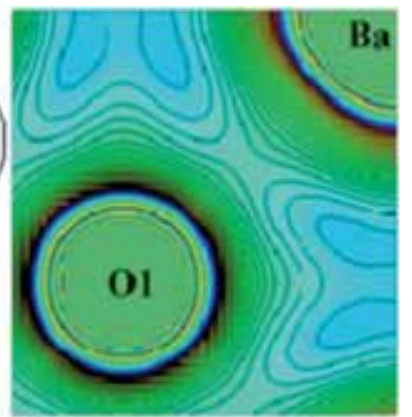

(b)

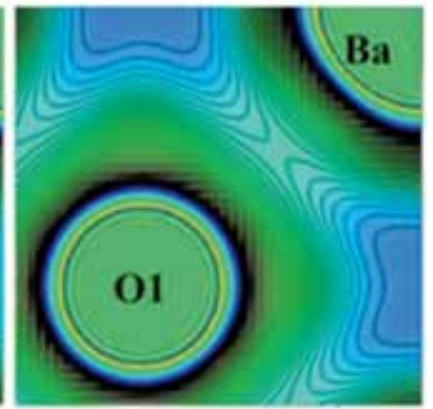

(d)

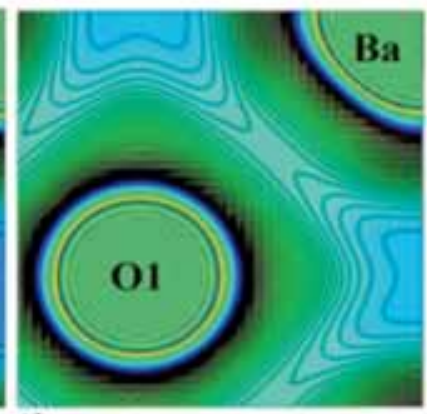

(f)

Figure 5. (a) 2D electron density distributions on (001) plane for $x=0.000$. (b), (c), (d), (e) and (f) are enlarged views of bonding between $\mathrm{Ba}$ and $\mathrm{O} 1$ atoms for compositions $\mathrm{x}=0.000, \mathrm{x}=0.005, \mathrm{x}=0.015, \mathrm{x}=0.020$ and $\mathrm{x}=0.025$.

nature between barium and oxygen. The mid bond density between Ti-O2 bond for the undoped sample is $0.674 \mathrm{e} / \AA^{3}$ and for the doped samples the mid bond density values are $0.649 \mathrm{e} / \AA^{3}, 0.659 \mathrm{e} / \AA^{3}, 0.742 \mathrm{e} / \AA^{3}$ and $0.724 \mathrm{e} / \AA^{3}$ which is evidence for the enhancement of covalent nature of Ti-O2 bond. No significant changes in the mid bond density values were observed with $\mathrm{La}$ addition. According to defect chemistry, $\mathrm{La}^{3+}$ substitution for $\mathrm{Ba}^{2+}$ on the A-site of $\mathrm{BaTiO}_{3}$ creates charge imbalance which should be compensated by either A-site cation vacancies $\left(\mathrm{V}_{\mathrm{Ba}}\right)$ or B-site cation vacancies $\left(\mathrm{V}_{\mathrm{Ti}}\right)$ or by electrons through three different charge compensation mechanisms. ${ }^{36}$ It was reported that, the solid solutions prepared with the formula $\mathrm{Ba}_{1-\mathrm{x}} \mathrm{La}_{\mathrm{x}} \mathrm{Ti}_{1-\mathrm{x} / 4} \mathrm{O}_{3}$ create $\mathrm{B}$-site cation vacancy $\left(\mathrm{V}_{\mathrm{Ti}}\right)$ and with the formula $\mathrm{Ba}_{1-\mathrm{x}} \mathrm{La}_{\mathrm{x}} \mathrm{TiO}_{3}$ provides additional electrons to the system..$^{37,38}$

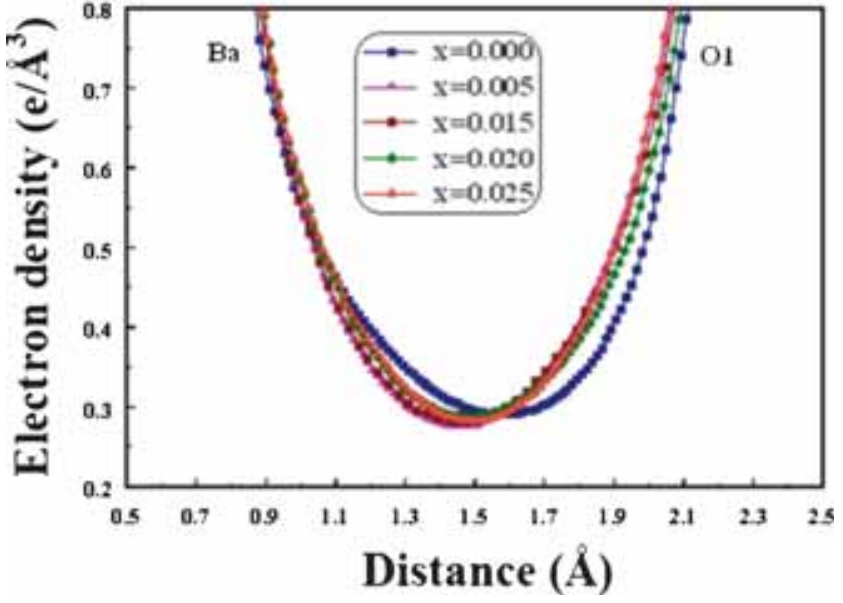

Figure 6. One dimensional line profiles for Ba-O1 bonds.

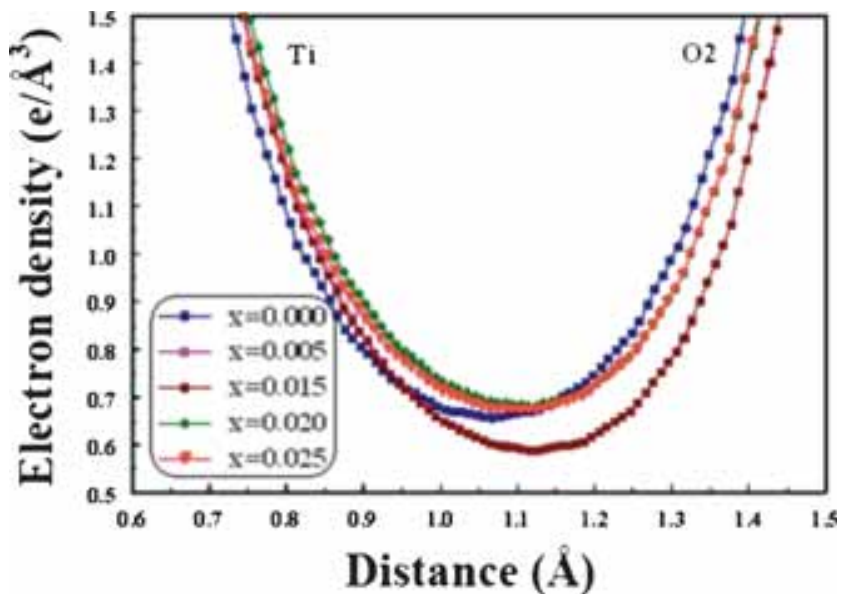

Figure 7. One dimensional line profiles for Ti-O2 bonds.

In this work, $\mathrm{La}$ doped $\mathrm{BaTiO}_{3}$ was prepared according to the formula $\mathrm{Ba}_{1-\mathrm{x}} \mathrm{La}_{2 \times / 3} \mathrm{TiO}_{3}$ and these solid solutions are charge compensated by A-site cation vacancies $\left(\mathrm{V}_{\mathrm{Ba}}\right)$. The number of cation vacancy increases with increasing La doping concentration on the $\mathrm{BaTiO}_{3}$ host lattice. ${ }^{39}$ The mid bond electron density values do not change with La doping, and this fact may be attributed to the presence of cation vacancies. La doped $\mathrm{BaTiO}_{3}$, charge compensated in this way, should remain insulating due to the immobility of cation vacancies.

La impurity addition also reduces the bond lengths between atoms in the unit cell, which is due to the lattice shrinkage comparable with the XRD results. Thus, the bonding features and electron density redistributions are clearly explained qualitatively as well as quantitatively using maximum entropy method.

\subsection{SEM analysis}

The micro structure and surface morphology of the prepared samples were analyzed by scanning electron 
Table 2. One dimensional electron density variation along Ba-O1 and Ti-O2 bonds.

\begin{tabular}{lcccc}
\hline $\begin{array}{l}\mathrm{La} \\
\text { Concentration }\end{array}$ & $\begin{array}{c}\text { Bond length } \\
(\mathrm{Ba}-\mathrm{O} 1) \\
(\AA)\end{array}$ & $\begin{array}{c}\text { Mid bond } \\
\text { density (Ba-O1) } \\
\left(\mathrm{e} / \AA^{3}\right)\end{array}$ & $\begin{array}{c}\text { Bond length } \\
(\mathrm{Ti}-\mathrm{O} 2) \\
(\AA)\end{array}$ & $\begin{array}{c}\text { Mid bond } \\
\text { density (Ti-O2) } \\
\left(\mathrm{e} / \AA^{3}\right)\end{array}$ \\
\hline $\mathrm{x}=0.000$ & 2.833 & 0.309 & 2.003 & 0.674 \\
$\mathrm{x}=0.005$ & 2.829 & 0.278 & 2.000 & 0.649 \\
$\mathrm{x}=0.015$ & 2.828 & 0.283 & 1.999 & 0.659 \\
$\mathrm{x}=0.020$ & 2.825 & 0.293 & 1.998 & 0.742 \\
$\mathrm{x}=0.025$ & 2.824 & 0.288 & 1.997 & 0.724 \\
\hline
\end{tabular}

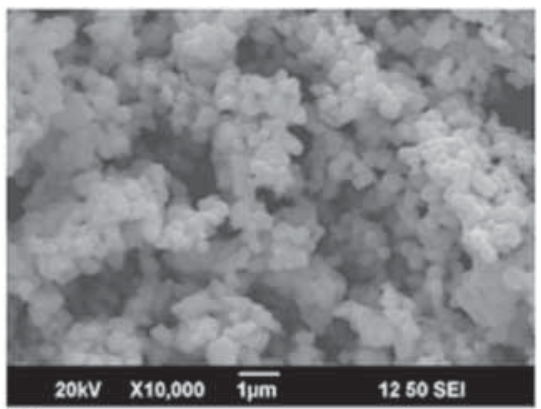

(a)

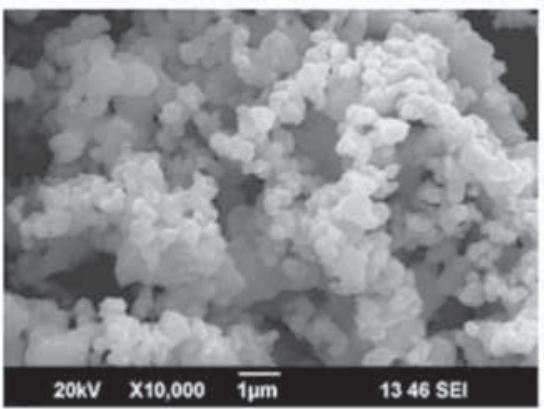

(b)

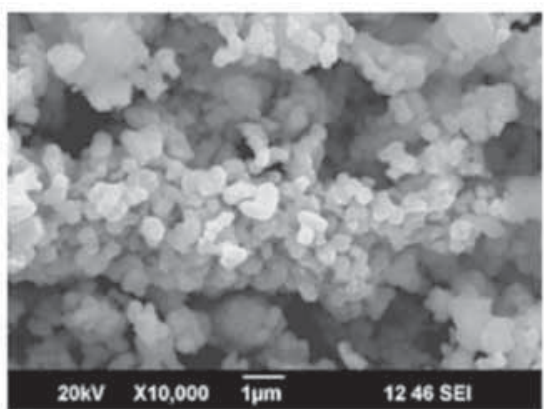

(c)
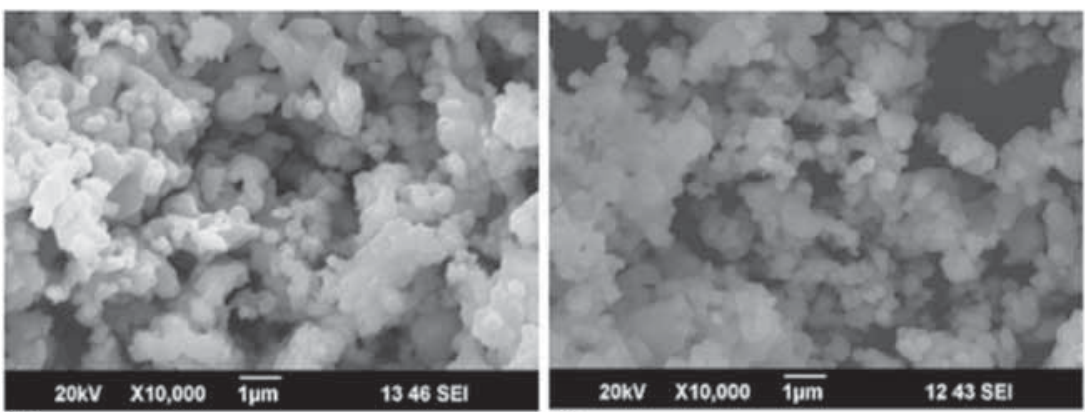

(d)

(e)

Figure 8. (a)-(e) SEM micrographs at the $\times 10000$ magnification level for the systems $\mathrm{Ba}_{1-\mathrm{x}} \mathrm{La}_{2 \mathrm{x} / 3} \mathrm{TiO}_{3}$ for $\mathrm{x}=0.000, \mathrm{x}=0.005, \mathrm{x}=0.015, \mathrm{x}=0.020$ and $\mathrm{x}=0.025$.

microscopy (SEM). SEM images corresponding to $\times 10000$ magnification are given in the Figures 8(a-e). The fine-grained micro structures of fairly narrow size particle distribution are evident for the undoped and low-level lanthanum doped samples. The micro structures also consist of large voids in between them, which are clearly visible from SEM micrographs.

\section{Conclusions}

$\mathrm{Ba}_{1-\mathrm{x}} \mathrm{La}_{2 \mathrm{x} / 3} \mathrm{TiO}_{3}(\mathrm{x}=0.000,0.005,0.015,0.020$ and 0.025 ) ceramic samples were synthesized by chemical route. The influence of $\mathrm{La}$ doping in the $\mathrm{BaTiO}_{3}$ structure and electron density re-distributions were investigated. Substitution of $\mathrm{La}$ at the $\mathrm{Ba}$ site suggested 
the reduction in lattice parameters and shrinkage in cell volume. Average grain sizes were found to be in the range of $21-36 \mathrm{~nm}$. The mid bond electron density values derived from the maximum entropy method (MEM) revealed the enhancement of the covalent nature between titanium and oxygen ions and predominant ionic nature between barium and oxygen ions. Observed variations of bond lengths and mid bond density values are due to the combined effects of A-site cation vacancies and lower ionic radius of $\mathrm{La}^{3+}$ than that of $\mathrm{Ba}^{2+}$. SEM investigations showed the existence of smaller grains with large voids in between them.

\section{Supplementary Information (SI)}

Additional information pertaining to the analysis of chemical bonding in $\mathrm{Ba}_{1-x} \mathrm{La}_{2 \times / 3} \mathrm{TiO}_{3}$, the $3 \mathrm{D}$ and $2 \mathrm{D}$ electron density distribution with the enlarged views of bonding are shown in Figures S1, S2 and S3, which are available at www.ias.ac.in/chemsci.

\section{Acknowledgements}

The authors gratefully acknowledge the authorities of The Madura College, Madurai 625011 for providing lab facilities, continuous support and encouragement to carry out this research work successfully. One of the authors ( $\mathrm{J} \mathbf{M})$ is thankful to the Management of NMSSVN College, Nagamalai, Madurai 625019 and UGC for the Faculty Development Programme of XII plan, the period in which this work was carried out.

\section{References}

1. Vasilescu C A, Curecheriu L P, Mitoşeriu L and Ianculescu A C 2015 UPB Sci. Bull. Ser. B 7795

2. Yoon D-H 2006 J. Ceram. Process Res. 7343

3. Dimitrovska-Lazova S, Aleksovska $\mathrm{S}$ and Tzvetkov $\mathrm{P}$ 2015 J. Chem. Sci. 1271173

4. Wang S-F, Hsu Y-F, Huang H-S and Liu Y-J 2011 Ceram. Int. 371327

5. Chou X, Zhao Z, Zhang W and Zhai J 2010 Mater. Des. 313703

6. Melo D M A, César A, Martinelli A E, Silva Z R, Leite E R, Longo E and Pizannic P S 2004 J. Solid. State. Chem. 177670

7. Maa N, Zhang B-P, Yang W-G and Guob D 2012 J. Eur. Ceram. Soc. 321059

8. Li W, Xu Z, Chu R, Fu P and Hao J 2010 J. Alloy. Compd. 499255

9. Glinchuk M D, Bykov I P, Kornienko S M, Laguta V V, Slipenyuk A M, Bilous A G, V'yunov O I and Yanchevskiib O Z 2000 J. Mater. Chem. 10941
10. Buscaglia M T, Buscaglia V, Viviani M, Nanni P and Hanuskova M 2000 J. Eur. Ceram. Soc. 201997

11. Valdez-Nava Z, Tenailleau C, Guillemet-Fritsch S, El Horr N, Lebey T, Dufour P, Durand B and ChaneChing J Y 2010 J. Phys. Chem. Solids 7217

12. Castro M S, Salgueiro W and Somozab A 2007 J. Phys. Chem. Solids 681315

13. Freeman C L, Dawson J A, Chen H-R, Ben L, Harding J H, Morrison F D, Sinclair D C and West A R 2013 Adv. Funct. Mater. 233925

14. Brutchey R L, Cheng G, Qian G and Morse D E 2008 Adv. Mater. 201029

15. Wada S, Yasuno H, Hoshina T, Nam S-M, Kakemoto $H$ and Takaaki T 2003 J. Appl. Phys. 426188

16. Lin T-F and Hu C-T 1990 J. Am. Ceram. Soc. 73531

17. Saravanan R 2009 Phys. Scr. 791

18. Evarestov R A, Smirnov V P and Usvyat D E 2003 Solid. State. Commun. 127423

19. Kutty T R N 1986 J. Chem. Sci. 96581

20. Tiwari R M, Gadhvi M, Nag A, Vasanthacharya N Y and Gopalakrishnan J 2010 J. Chem. Sci. 122529

21. Syed Ali K S, Saravanan R, Pashchenko A V and Pashchenko V P 2010 J. Alloy. Compd. 501307

22. Collins D M 1982 Nature 29849

23. Rother A, Reibold M and Lichte H 2006 Phys. Rev. B 74 $134116(1-8)$

24. Shannon R D 1976 Acta. Crystallogr. 32751

25. Wenhu Y, Yongping P, Xiaolong C and Jinfei W 2009 JPCS 152012040

26. Urek S, Drofenik M and Makovec D 2000 J. Mater. Sci. 35895

27. Lin M-H and Lu H-Y 2002 Mater. Sci. Eng. A323 167

28. Rietveld H M 1969 J. Appl. Crystallogr. 265

29. Petricek V, Dusek M and Palatinus L 2000 In The Crystallographic Computing System JANA 2006 (Praha: Institute of Physics, Academy of Sciences of the Czech Republic)

30. Wyckoff R W G 1963 In Crystal Structures 1 (London: Inter-space Publishers)

31. Wodecka-Dus B and Czekaj D 2009 Arch. Metall. Mater. 54923

32. Gorelov B M, Kotenok E V, Makhno S N, Sydorchuk V V, Khalameida S V and Zazhigalov V A 2011 Solid State Electron $\mathbf{5 6} 83$

33. Vijatovic M M, Stojanovic B D, Bobic J D, Ramoska T and Bowen P 2010 Ceram. Int. 361817

34. Ruben A D and Izumi F 2004 Super-fast Program PRIMA for the Maximum-Entropy Method (Tsukuba, Ibaraki: Advanced Materials Laboratory, National institute for materials science)

35. Momma K and Izumi F 2008 J. Appl. Crystallogr. 41 653

36. Morrison F D, Coats A M, Sinclair D C and West A R 2001 J. Electroceram. 6219

37. Chen Y L and Yang S F 2011 Adv. Appl. Ceram. 110257

38. Morrison F D, Sinclair D C and West A R 1999 J. Appl. Phys. 866355

39. Ganguly M, Rout S K, Sinha T P, Sharma S K, Park H Y, Ahn C W and Kim I W 2013 J. Alloy. Compd. 579473 